\title{
Evaluating the cost-effectiveness of catheter ablation of atrial fibrillation
}

\author{
Chukwuemeka Daniel Iroegbu, Wangping Chen, Xun Wu, Luo Cheng, Hao Zhang, Ming Wu, \\ Yuan Zhao, Li Ming Liu, Jinfu Yang \\ Department of Cardiovascular Surgery, Second Xiangya Hospital, Central South University, Changsha, China \\ Contributions: (I) Conception and design: CD Iroegbu; (II) Administrative support: J Yang, LM Liu; (III) Provision of study materials or patients: \\ J Yang, LM Liu; (IV) Collection and assembly of data: All authors; (V) Data analysis and interpretation: CD Iroegbu, L Cheng, H Zhang; (VI) \\ Manuscript writing: All authors; (VII) Final approval of manuscript: All authors. \\ Correspondence to: Li Ming Liu; Jinfu Yang. Department of Cardiovascular Surgery, Second Xiangya Hospital, Central South University, Middle \\ Renmin Road 139, 410011 Changsha, China. Email: liulimingiia@aliyun.com; yjf19682005@csu.edu.cn.
}

Background: The pursuit of a clearer understanding of the pathogenesis of atrial fibrillation (AFib) and the development of new technology has resulted in a surge of interest in the surgical ablation for AFib. Here, we report our 8-year experience in the surgical treatment and management of AFib alongside, evaluating the cost-effectiveness in southern Mainland China over a 1-year follow-up.

Methods: Data of 3,068 patients from March 2011 through June 2019 was retrospectively extracted from The Provincial National Cardiac Database of Xiangya Second Hospital. The activities considered (and costs calculated) were outpatient consultations, hospital admissions, and drug treatment. Quality of life (QoL) questionnaires were also carried out to assess whether concomitant AFib correction procedures increase risk in patients, or improve patient's QoL.

Results: A total of 3,068 patients completed the questionnaires at a minimum of one time-point during the follow-up. The total cost was combined to obtain incremental costs per quality-adjusted life-years (QALYs). The total costs of the AFib catheter ablation group were remarkably higher compared to surgery as usual group. The incremental cost-effectiveness ratio was \$76,513,227 (¥542,287,667) per QALY, with an acceptability line graph for cost at $43 \%$.

Conclusions: AFib is an extraordinarily costly and worrisome public health problem. Precision medicine is vital as it provides a platform for the clinical translation of targeted interventions that are designed to help treat and prevent AFib. Thus, to improve the QoL expectancy outcome(s), both therapeutic and surgical interventions should be aimed at addressing the underlying heart disease rather than restoring sinus rhythm.

Keywords: Atrial fibrillation (AFib); cost-effectiveness; Maze procedure; surgical ablation; quality-adjusted life year (QALY)

Submitted Jun 17, 2020. Accepted for publication Jul 31, 2020.

doi: $10.21037 / \mathrm{cdt}-20-574$

View this article at: http://dx.doi.org/10.21037/cdt-20-574

\section{Introduction}

Atrial fibrillation (AFib) is an age-related arrhythmia of significant global public health concern $(1,2)$ characterized by chaotic contractions of the atrium. This abnormal heart rhythm is also enhanced by the associated clinical risk factors (rheumatic and nonrheumatic valve diseases, congestive heart failure, diabetes, myocardial infarction, and hypertension), and echocardiographic risk factors for nonrheumatic AFib, left atrial enlargement and the thickened left ventricular wall $(3,4)$. Patients with AFib are hospitalized twice as often as those without AFib, and accordingly so, increasing both clinical and translational research efforts $(5,6)$. AFib is associated with increased 
mortality if left untreated and in some population, increased morbidity. Currently, in the health sector, the incremental costs attributable to AFib-related care still pose a challenge for healthcare providers (7-9). With this in mind, cardiac surgeons now provide patients with a complete operation employing a variety of ablation technologies currently available. Although current evidence suggests that the addition of a Maze procedure improves the overall quality of life (QoL) (10), the choice of lesion set and the rationale for surgical ablation remain a difficult problem to deal with in modern practice today. Affecting more than 2.5 million individuals in the United States (11-14), it has become clear that aging, cardiac and noncardiac conditions, genetics, and environmental factors, further contribute to a favorable atrial substrate (15).

Indeed, significant advances have been made down the years; however, some key challenges remain such as defining and reporting sinus rhythm restoration "success" or "failure", uniform standards for reporting results, the rationale for surgical ablation, and development of improved technology for ablative intraoperative assessments $(16,17)$. However, with the various challenges, few surgeons offer such major surgery with ablation to relatively symptomatic and asymptomatic AFib patients. The surgery offered could either be as a concomitant or a stand-alone operation based on the various clinical guidelines $(7,8,18,19)$ even from the most recent 2017 Society of Thoracic Surgeons guidelines (STS) (20). Thus, according to the STS guidelines, which carefully state "to restore sinus rhythm as the purpose for intervention rather than to improve survival and QoL" further adds to the definite need for surgery perhaps after the failure of drug and catheter therapy. Central to these, integrating observational findings and basic sciences into a defined therapeutic strategy would prove vital for any required progress in clinical practice (21) where such ambiguity exists. Currently, in "real-world" practice, there are insufficient randomized clinical controlled trial data to support the needs of clinicians (22).

According to our knowledge, there are no retrospective studies on cost-effectiveness for add-on ablation surgery in Mainland China. Hence, we designed the study aimed at assessing the cost-effectiveness of surgical ablation in Southern Mainland China, health-related quality of life (HrQoL), and the associated risk of morbidity or mortality for these AFib patients over a 1-year follow-up period. The study, however, goes further in providing answers to the open-ended question in practice today: (I) should we still carry out surgical AFib ablations, not minding the cost implications? (II) should AFib ablation be provided as a surgical treatment option for patients with currently no standardized rationale (diverse ablation practices), and the underrepresentation of long-term patient-reported outcomes within existing AFib intervention trials? We present the following article in accordance with the MDAR reporting checklist (available at http://dx.doi.org/10.21037/ cdt-20-574).

\section{Methods}

Data of patients (AF catheter ablation group 3,068 patients) were retrospectively extracted from The National Provincial Cardiovascular Research Database of Xiangya Second Hospital, which is the designated regional hospital for treating AFib patients within Southern and Central South Mainland China. It is a voluntary cardiac surgery database established between 2011 and 2012 to support and improve the national surgical outcome of AFib treatment. It contains detailed perioperative data on all AFib surgical procedures performed in the institution. The research database is approved by the Institutional Review Board at Central South University Xiangya School of Medicine (project No. 2018YFC1311204). Accordingly, data from Xiangya Second Hospital for patients (surgery as usual group, 7,258 patients) were retrospectively extracted from the hospital's patients' general surgical archives (Medical Records Department Fu Er Cardiac Surgery Third Division). Patients, who, however, refused participation in this project were not included in the study. The surgical indication for all patients (AFib catheter ablation group) was preoperative AFib, and 341 had a prior catheter ablation.

\section{Patient population}

All patients from The National Provincial Cardiovascular Research Database of Xiangya Second Hospital from March 2011 through June 2019 (AFib catheter ablation group), and January 2001 through February 2011 (surgery as usual) were included in this study. For this study, we only focused on patients undergoing concomitant AFib surgery with valvular heart diseases (mitral and aortic), and coronary artery bypass graft (CABG) for cost-effectiveness and outcome analysis. We excluded high-risk individuals such as patients with myocardial infarction within 1 day of surgery, cardiogenic shock, percutaneous coronary intervention within 6 hours, ongoing cardiopulmonary resuscitation, and even dialysis. All patients were in New York Heart 
Association (NYHA) functional class III or IV at the time of the surgery (Table 1).

\section{Study design}

The economic evaluation and cost analysis of this study were based on a single institutional report of 7,258 (surgery as usual) patients without AFib intervention procedure, and 3,068 AFib patients (AFib catheter ablation group) who had concomitant ablation. The cost analysis also included a contemporary societal prevalence-based approach for surgical ablation in Southern Mainland China. Although the meaning of HrQoL may vary, it can, however, generally be assessed based on the following parameters: physical condition, social activities, psychological well-being, and everyday activities $(23,24)$. All the patients included in this study had a history of documented paroxysmal or persistent AFib for at least 3 months before surgery, as defined by the American College of Cardiology (ACC)/American Heart Association (AHA)/European Society of Cardiology (ESC) guidelines (25). HrQoL and maintenance of sinus rhythm at 1-year follow-up after surgery were considered as primary endpoints of the total study with cost-effectiveness, morbidity, and mortality as secondary outcomes. All patients completed the three postoperative questionnaires used in the study. Both groups were kept blinded to all medical personnel and patients except for the surgical team to limit healthcare consumption confounding factors during the follow-up period.

\section{Surgical procedure (add-on arrbythmia surgical procedure)}

All patients in the AFib catheter ablation group underwent a complete Maze IV procedure with radiofrequency energy bipolar Cardioblate device used to produce linear ablation lines, and also had their left atrial appendix excised (26). Double ablations were correctly applied when ablating the thicker pulmonary vein regions. Epicardial cardioversion was attempted 3-4 times in the isolated CABG group before commencing ablation therapy in order to bring the patients into sinus rhythm and to facilitate the ablative effects. Before the institution of CABG, surgical ablation procedure was performed first thus, allowing epicardial off-pump beating heart ablation. The pericardial reflection between the superior and inferior right pulmonary vein, the superior and inferior caval vein into the oblique sinus, and the transverse sinus were opened. Fatty tissues around the roof of the left atrium in the transverse sinus and along the intra- atrial groove were dissected. The left atrial appendage was resected, and an appropriate sling was positioned along the transverse sinus, while another was passed across from the inferior pulmonary vein through the oblique sinus into the transverse sinus. Additional pacing wires were placed behind the right atrial appendage and close to the interventricular septum to evaluate rate and rhythm (conduction block) during the postoperative period. The off-pump beating heart ablation procedure for the isolated CABG group was performed according to the standard protocol $(7,8,18-20)$.

\section{Outcomes}

The primary outcome was operative mortality, which was seen as $\geq 30$ day or in-hospital mortality. Other additional issues determined included prolonged ventilation, the need for permanent pacemaker implantation, stroke, reoperation for bleeding, renal failure, deep sternal wound infection, and dialysis (Table 2).

\section{HrQoL questionnaires}

Both disease-specific and generic measurements were covered for a comprehensive HrQoL assessment. The RAND 36-item Health Survey 1.0 (SF-36) comprising eight multi-item scales (27) and the European quality of life (EuroQoL) generic questionnaire used in this study are both validated, standardized, and frequently used in arrhythmia studies $(25,28)$. They have both been successfully and actively used in cost-effectiveness and HrQoL research for heart patients $(29,30)$. The EuroQoL consists of two components: the EuroQoL classification (EQ-5D, mobility, self-care, usual activities, pain/discomfort, and anxiety/ depression), and description of the respondent's health using the EuroQoL thermometer (VAS, a visual analog scale) (24). The disease-specific questionnaire used was the Multidimensional Fatigue Inventory (MFI-20) (31). All questionnaires in this study for both surgeries as usual group and AFib catheter ablation group were selfadministered at the hospital (baseline) and were then sent by post or answered during clinic visits during the follow-up period of 1 year at 3, 6, and 12 months after surgery. Scales were determined, ranging from one (highest well-being) to five (lowest well-being).

\section{QoL measurements}

For the economic evaluation, the effectiveness was 
Table 1 Relevant clinical characteristics for "add-on" patients who underwent valvular surgery, CABG, and concomitant Cox-Maze IV procedure in each subcategory $v s$. "surgery as usual"

\begin{tabular}{|c|c|c|c|c|c|}
\hline $\begin{array}{l}\text { Operation type \& number of } \\
\text { patients }\end{array}$ & $\begin{array}{l}\text { Mitral + tricuspid + } \\
\text { CABG + Cox Maze } \\
\text { IV }(\mathrm{N}=1,012)\end{array}$ & $\begin{array}{l}\text { Aortic + CABG } \\
+ \text { Cox Maze IV } \\
\quad(\mathrm{N}=819)\end{array}$ & $\begin{array}{c}\text { Mitral + tricuspid +aortic } \\
+ \text { CABG + Cox Maze IV } \\
(N=1,146)\end{array}$ & $\begin{array}{l}\text { Isolated CABG } \\
+ \text { Cox Maze IV } \\
\quad(\mathrm{N}=91)\end{array}$ & $\begin{array}{l}\text { Surgery as usual } \\
\qquad(\mathrm{N}=7,258)\end{array}$ \\
\hline Age (years) & $54.6 \pm 10.1$ & $58.4 \pm 12.7$ & $70.9 \pm 8.1$ & $57.5 \pm 13.3$ & $60.3 \pm 14.9$ \\
\hline Weight (kg) & $62.8 \pm 7.8$ & $62.5 \pm 4.0$ & $57.0 \pm 9.3$ & 67.0 & $60.7 \pm 11.0$ \\
\hline \multicolumn{6}{|l|}{ Type of AFib } \\
\hline Paroxysmal & $494(48.8)$ & $336(41.0)$ & $547(47.7)$ & $61(67.0)$ & $3170(43.7)$ \\
\hline Persistent & $292(28.9)$ & $341(41.6)$ & $357(31.2)$ & 0 & $1998(27.5)$ \\
\hline Longstanding persistent & $226(22.3)$ & $142(17.3)$ & $242(21.1)$ & $30(33.0)$ & $2661(36.7)$ \\
\hline Diabetes & $7(0.7)$ & $5(0.6)$ & $9(0.8)$ & $3(3.3)$ & $21(0.3)$ \\
\hline Congenital & 0 & 0 & 0 & 0 & 0 \\
\hline Hypertension & $157(15.5)$ & $83(10.1)$ & $277(24.2)$ & 0 & $472(6.5)$ \\
\hline \multicolumn{6}{|l|}{ Renal failure } \\
\hline Previous pacemaker & 0 & 0 & 0 & 0 & 0 \\
\hline Previous CVA/TIA & $1(0.1)$ & $1(0.1)$ & $1(0.1)$ & $3(3.3)$ & $17(0.2) / 8(0.1)$ \\
\hline Prior valvular and CABG surgery & 0 & 0 & 0 & 0 & 0 \\
\hline \multicolumn{6}{|l|}{ Pre-operative complaints } \\
\hline Dizziness & $108(10.7)$ & $819(100.0)$ & $226(19.7)$ & $91(100.0)$ & $3,670(50.6)$ \\
\hline Other complaints & $180(17.8)$ & $426(52.0)$ & $1(0.1)$ & $91(100.0)$ & $1,899(26.2)$ \\
\hline \multicolumn{6}{|l|}{ Postoperative rhythm } \\
\hline Atrioventricular block & $1(0.1)$ & $1(0.1)$ & $13(1.1)$ & $57(62.6)$ & $1,372(18.9)$ \\
\hline Atrial fibrillation & $783(77.4)$ & $818(99.9)$ & $313(27.3)$ & $33(36.3)$ & $5,719(78.8)$ \\
\hline Atrial flutter & $8(0.8)$ & $5(0.6)$ & $11(1.0)$ & $7(7.7)$ & $11(0.2)$ \\
\hline Temporary pacemaker & 0 & $292(35.7)$ & 0 & 0 & $1,763(24.3)$ \\
\hline Permanent pacemaker & $588(58.1)$ & $62(7.6)$ & $304(26.5)$ & 0 & $1,137(15.7)$ \\
\hline \multicolumn{6}{|l|}{ Postoperative cardioversions } \\
\hline Electrical & $1(0.1)$ & $696(85.0)$ & $473(41.3)$ & $91(100.0)$ & $1,268(17.5)$ \\
\hline Pharmacological & $1,011(99.9)$ & $123(15.0)$ & $158(13.8)$ & 0 & $5,065(69.8)$ \\
\hline
\end{tabular}

Data presented as mean \pm SD or $n(\%)$. AFib, atrial fibrillation; CABG, coronary arterial bypass; LVEF, left ventricular ejection fraction; MI, myocardial infarction; CVA, cerebrovascular accident; TIA, transient ischemic attack. 
Table 2 Outcomes for "add-on" patients who underwent valve surgery, CABG, Cox-Maze procedure in each subcategory vs. "surgery as usual"

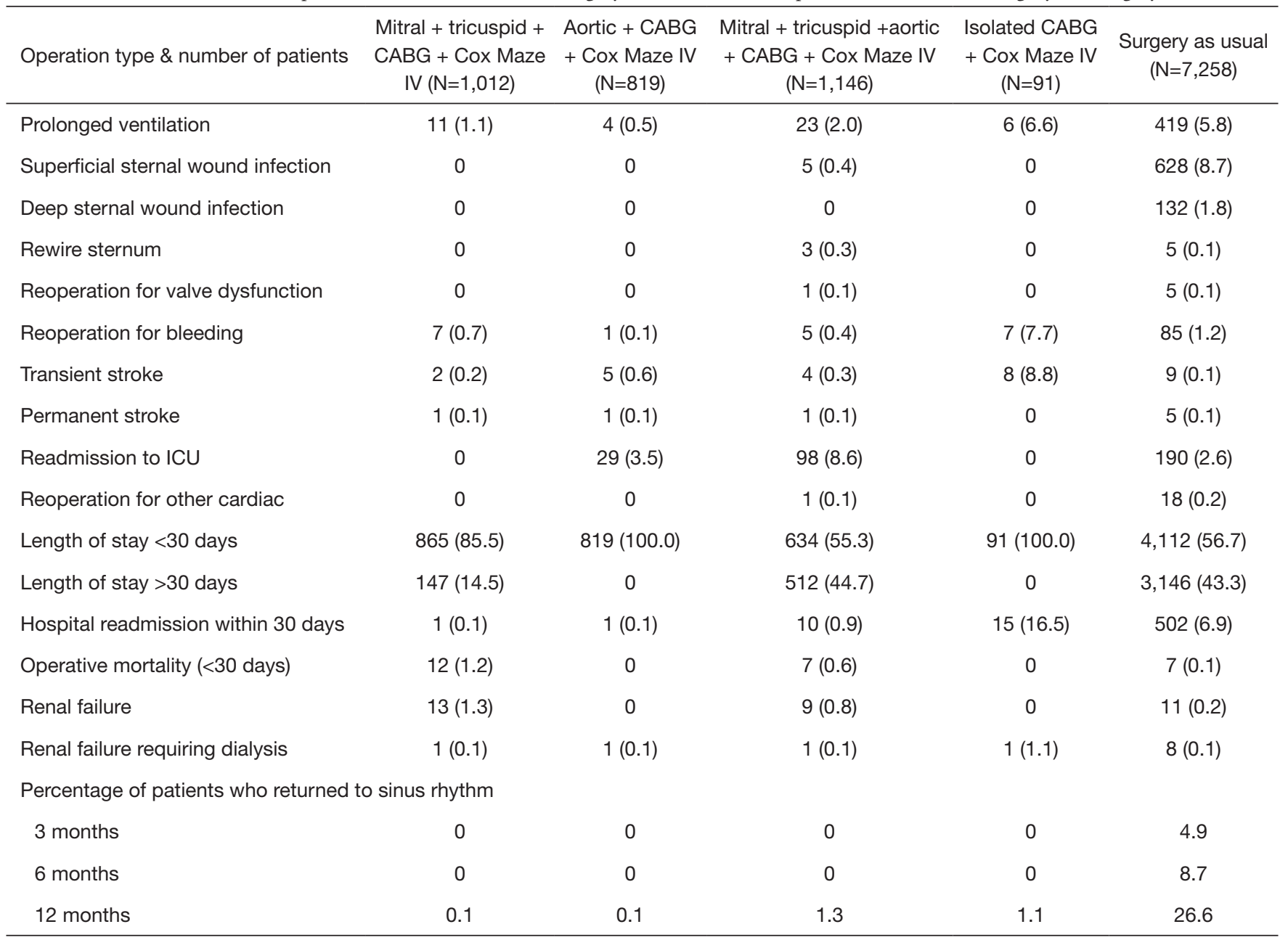

Data presented as mean \pm SD or $n(\%)$. ICU, intensive care unit; CABG, coronary arterial bypass.

expressed as quality-adjusted life-years (QALYs). The HrQoL was assessed by SF-36, EuroQoL, and the MFI-20 at baseline, 3, 6, and 12 months after the surgery $(24,27)$. Using the Dolan algorithm, patients' responses to both disease-specific and generic measurements QoL questioners were converted to utility scores to calculate the QALY. The maximum number of QALYs within this study is one [1-year follow-up in perfect health $(=1)$ multiplied with one].

\section{Resources or volumes used and long-term care}

The effects and costs of AFib healthcare utilization continuously recorded by participants were collected during 1 year, at baseline, 2-6 weeks, 3-4 months, 6-7 months, and 11-12 months using the cost diary method (32). From a contemporary societal perspective, the diary contained questions regarding three categories of costs: direct healthcare costs, direct non-healthcare costs, and indirect healthcare costs (Table 3). To calculate the incremental cost-effectiveness ratio (ICER), the cost difference of both groups was divided by the gain in HrQoL. The result was hence, defined as the incremental costs per QALY.

\section{Unit prices}

The unit costs for hospitalization and surgery days were derived from the hospital information system, societal perspective, and the hospital financial institute for patient's welfare. Total operative costs included both the actual operation time and the time the patients spent in the 
Table 3 Mean unit costs in yuan per category used for "add-on" patients who underwent valvular surgery, CABG, and concomitant Cox-Maze IV procedure $v s$. "surgery as usual"

\begin{tabular}{|c|c|c|c|c|c|c|}
\hline $\begin{array}{l}\text { Intervention groups add-on group \& } \\
\text { surgery as usual }\end{array}$ & Unit & Mean & $\begin{array}{c}\text { Standard } \\
\text { deviation }( \pm)\end{array}$ & $\begin{array}{l}\% \text { cost } \\
\text { per unit }\end{array}$ & $\begin{array}{l}\text { Total cost }(\$) \\
\text { per unit }\end{array}$ & $\begin{array}{l}\text { Source HIS, } \\
\text { HFIPW \& SP }\end{array}$ \\
\hline \multicolumn{7}{|l|}{ Direct health care cost } \\
\hline ACC & Surgery & $140,061.1$ & $1,747.1$ & 10.3 & $16,405,734$ & HIS \\
\hline ICC & Surgery & $90,000.0$ & 0.0 & 0.7 & $1,171,319$ & HIS \\
\hline MTCC & Surgery & $155,000.0$ & 0.0 & 14.1 & $22,434,007$ & HIS \\
\hline SAU & Surgery & $84,927.0$ & $8,112.6$ & 55.4 & $88,157,097$ & HIS \\
\hline \multicolumn{7}{|l|}{ Medication } \\
\hline ACC & Fixed & $20,000.0$ & 0.0 & 13.2 & $2,342,888$ & HIS \\
\hline SAU & Fixed & $8,621.4$ & 925.6 & 50.5 & $8,950,389$ & HIS \\
\hline \multicolumn{7}{|l|}{ Hospital stay } \\
\hline ACC & Fixed & $1,260.0$ & 0.0 & 5.5 & 147,598 & HIS \\
\hline ICC & Fixed & $1,260.0$ & 0.0 & 0.6 & 16,399 & HIS \\
\hline MTACC & Fixed & $2,617.1$ & 301.0 & 16.1 & 428,959 & HIS \\
\hline MTCC & Fixed & $1,496.6$ & 492.3 & 2.6 & 68,482 & HIS \\
\hline SAU & Fixed & $1,932.9$ & 385.3 & 75.2 & $2,006,533$ & HIS \\
\hline \multicolumn{7}{|l|}{ Cardio surgeon consultation* } \\
\hline \multicolumn{7}{|l|}{ General practitioner* } \\
\hline ACC & Visit & 202.8 & 9.5 & 8.5 & 23,751 & HIS \& HFIPW \\
\hline ICC & Visit & 200.0 & 0.0 & 0.9 & 2,603 & HIS \& HFIPW \\
\hline MTACC & Visit & 202.3 & 2.3 & 11.8 & 33,162 & HIS \& HFIPW \\
\hline MTCC & Visit & 208.4 & 1.7 & 10.8 & 30,163 & HIS \& HFIPW \\
\hline SAU3 & Visit & 183.4 & 4.7 & 68.0 & 190,387 & HIS \& HFIPW \\
\hline \multicolumn{7}{|l|}{ Cardiologist consultation* } \\
\hline ACC & Visit & 234.2 & 19.5 & 8.3 & 27,428 & HIS \& HFIPW \\
\hline ICC & Visit & 200.0 & 0.0 & 0.8 & 2,602 & HIS \& HFIPW \\
\hline MTACC & Visit & 240.1 & 9.0 & 11.8 & 39,350 & HIS \& HFIPW \\
\hline MTCC & Visit & 242.0 & 9.2 & 7.1 & 23,738 & HIS \& HFIPW \\
\hline SAU & Visit & 230.0 & 0.0 & 72.0 & 331,840 & HIS \& HFIPW \\
\hline
\end{tabular}

Table 3 (continued) 
Table 3 (continued)

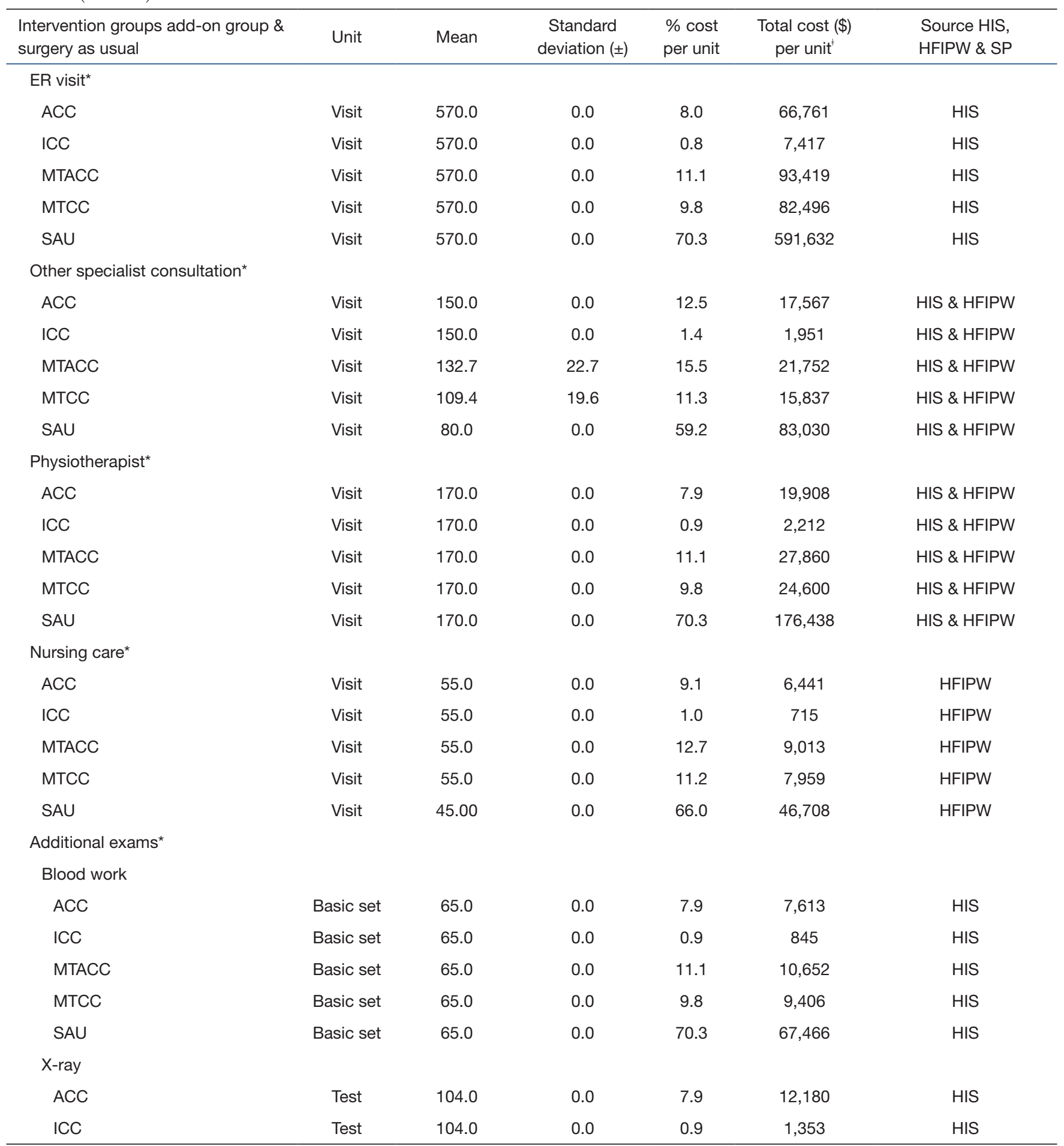

Table 3 (continued) 
Table 3 (continued)

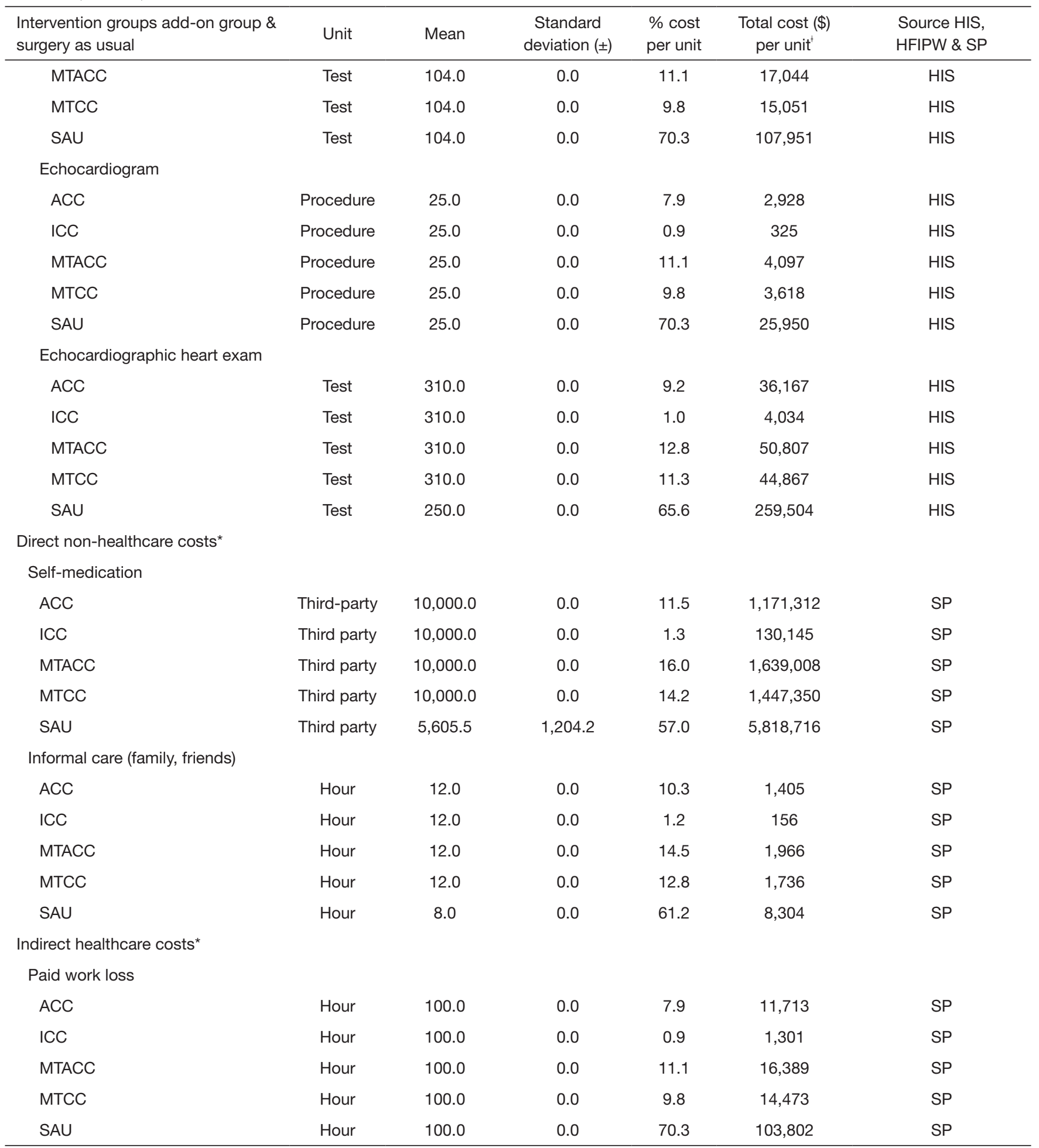

Data presented as mean \pm SD or percentage. *, after discharge; ${ }^{*}$, currency exchange rate at the $3^{\text {rd }}$ quarter of the year 2019. CABG coronary arterial bypass; ER, emergency room; HIS, Hospital Information System; HFIPW, Hospital Financial Institute for Patient's Welfare; SP, societal perspective; ACC, aortic + CABG + Cox-Maze IV; ICC, isolated CABG + Cox-Maze IV; MTACC, mitral + tricuspid + aortic + CABG + Cox-Maze IV; MTCC, mitral + tricuspid + CABG + Cox-Maze IV; SAU, surgery as usual. 
operating theatre. Additional catheter costs and prosthetic material for add-on surgery were also added to the total surgery costs. Costs regarding the overall hospital stay consisted of days in the intensive care unit, emergency room, medium care unit, and regular nursing department care. Medication costs were institutionally derived and asserted from the hospital pharmacological registry. The absence of paid work was calculated according to provincial and regional individual workers' organizational perspective(s). All costs are presented in dollars (\$) (Table 3 provides an overview of the costs unit).

\section{Clinical follow-up}

AFib was treated according to predefined protocols during in-hospital follow-up: oral anticoagulants depending on rhythm outcome for at least 3 to 4 months, prophylactic sotalol for at least 3 to 4 weeks postoperatively, additional digoxin for rate control, and cardioversion after three days of persistent AFib. Atrial arrhythmia in the followup period (out-patient-department) was treated by our hospital's therapeutic department cardiologist for rate control and cardioversion. An ECG was used to evaluate the patients' heart rhythm. All patients used oral anticoagulants as long as they were in AFib and for other non-AFib related diseases. Patients received $100 \mathrm{mg}$ of low-dose aspirin daily if none of these premises occurs. Patients' check-up was carried out at our outpatient clinics at 3, 6, and 12 months after surgery after postoperative discharge. A 24-hour Holter monitor was attached to patients at the 12 months for a day during the follow-up (Table 2).

\section{Statistical analysis}

The frequency of preoperative AFib and procedural AFib corrections were evaluated across the following operative categories which were all concomitant AFib procedures: mitral + tricuspid + CABG + Cox-Maze IV (MTCC), aortic + CABG + Cox-Maze IV (ACC), mitral + tricuspid + aortic + CABG + Cox-Maze IV (MTACC), and isolated CABG + Cox-Maze (ICC). Specific outcomes of interest, operative characteristics, risk factors, and demographic features such as age and sex were compared after the AFib correction procedure. For statistical analysis, SPSS for Windows Version 15.0 (SPSS Inc, Chicago, IL, USA) was used. Before cost prices were computed, mean imputation was performed at a variable level for the cost diary. Data were analyzed by the intention-to-treat in which mean substitution for missing cases was applied. Uncertainty intervals (UIs), mean cost difference, and the UIs surrounding the ICERs were employed to test the robustness of the cost analysis (33). Also, an acceptability line graph (AFib catheter ablation group vs. surgery as usual) was plotted to show the maximum amount patients or the society, in general, would be willing to pay for a gain in QALY and or effectiveness. The utility weight level for cardiovascular disease and a $3 \%$ discount rate was used, in line with the Global Burden of Disease study, while an average duration of the illness was fixed for both the groups. All continuous variables are presented as means and standard deviations. Group comparison between continuous variables was performed, using Student's t-test in case of normal distribution; otherwise, Mann-Whitney $\mathrm{U}$ test was applied. For all categorical data, the chi-square loglikelihood test was used. A $\mathrm{P}$ value $<0.05$ was considered to be statistically significant.

\section{Equations}

QALY's lived in 1 year $=1^{*} \mathrm{Q}$ with $\mathrm{Q} \leq 1 ; Q A L E=\sum_{t=a}^{n a+L} Q t$; discounted $Q A L E=\sum_{t=a}^{a+L} \frac{Q t}{(1+r) t-a}$.

$$
Q A L E=\int_{x=a}^{a+L} Q e^{-r(x-a)} d x=Q \frac{e^{-r L}}{r}
$$

$$
Q A L E^{\prime} s \text { gained }=Q^{i}=\frac{1-e^{-r L i}}{r}-Q=\frac{1-e^{-r L}}{r}
$$

(III) $Q A L E^{\prime}$ s gained $=\left(Q^{i}-Q\right) \frac{1-e^{-r L}}{r}$.

where $\mathrm{Q}=\mathrm{HrQoL} ; \mathrm{L}=$ the residual life expectancy of the individual at age $\mathrm{a} ; \mathrm{t}=$ individual years within that life expectancy range; $r=$ discount rate; $i=$ the improvement in QALE obtained through a specific health intervention; $\mathrm{e}=$ Napier's mathematical constant; $\mathrm{x}=$ the individual's age; Li and Qi are, respectively, the period over which treatment affects the individual's QoL, and the QoL weight with treatment; while $\mathrm{L}$ and $\mathrm{Q}$ are the corresponding parameters without treatment; QALE $=$ quality-adjusted life expectancy.

\section{Ethical issues}

The study was conducted in accordance with the 
Table 4 Incremental cost-effectiveness ratio for the additional catheter ablation surgery $v$ s. surgery as usual

\begin{tabular}{lccc}
\hline Procedure & Cost $\$(¥)$ & QALY & ICER costs per QALY \\
\hline Surgery as usual group $(\mathrm{n}=7,258)$ & $107,171,794(749,329,876)$ & 0.39 & - \\
Add-on group $(\mathrm{n}=3,068)$ & $85,455,126(597,489,329)$ & 0.11 & - \\
Incremental (surgery as usual add-on) & $21,425,632(151,840,547)$ & 0.28 & $76,513,227(542,287,667)$ \\
\hline
\end{tabular}

QALY, quality-adjusted life-year.

Declaration of Helsinki (as revised in 2013). The ethical committee for Xiangya Second Affiliated Hospital of Central South University approved the study (No. 2018YFC1311204). The patients gave written informed consent to be included in the study.

\section{Results}

\section{Patient's background characteristics and QoL}

Three thousand one hundred and sixty-five patients in this study completed at least one cost diary during the followup, which was analyzed in this study (AFib catheter ablation group). At baseline, HrQoL, and background characteristics in terms of comorbidity, demographic data, risk factors, and previous cardiac history were also examined and analyzed. No significant statistical differences exist between each patient's background characteristics.

\section{Cost analysis}

The results in Table 4 show the various cost categories in the study during the 1-year follow-up. Mean total for direct healthcare costs was significantly higher in the valvular groups (MTCC, ACC, and MTACC) as compared to the ICC group $(\mathrm{P}=0.001)$ as a result of much-prolonged surgery time and the combined costs for the mechanical or biological valve with the ablation catheter itself (see Table 3). Other subcategories (direct non-healthcare cost, and indirect healthcare cost), were variably comparable without significant differences.

\section{Adverse events and mortality}

During the postoperative in-hospital period, the number of infection rate, myocardial infarction, stroke, pulmonary complications, and renal failure showed no significant variable differences among all patient groups. The number of adverse events variably remained equally distributed among all patient groups during the 1-year follow-up period (see Table 2). The overall in- and out-hospital mortality rate ( $\leq 30$ days) was $1.9 \%(n=26): 12$ patients in the MTCC group, none in the ACC group, 7 in MTACC group, none in the ICC group, and 7 in surgery as usual group.

\section{Cost-effectiveness analysis}

After 1 year, the total QALYs for AFib catheter ablation group (MTCC, ACC, MTACC, and ICC), were 0.11 and 0.39 for surgery as usual group (see Table 4). Since the difference in total costs between both the groups was $\$ 21,425,632$ ( $¥ 151,840,547)$, the ICER mounted to $\$ 76,513,227$ ( $¥ 542,287,667)$ per QALY gained. As can be seen in Figure 1, though concomitant ablation surgery is quite effective concerning enhancing HrQoL; it is, however, more costly. The acceptability line graph (Figure 1) shows that for the ICER of $\$ 76,513,227$ ( $¥ 542,287,667$ ), the probability of simultaneous ablation surgery being more cost-effective than regular cardiac surgery is $43 \%$. The acceptability line graph shows that the probability of ablation surgery being more cost-effective than surgery as usual, does not go beyond 50\%.

\section{HrQoL measurements}

The response rate for the questionnaires during the 1-year follow-up in the study was similar for all the groups. Mean and standard deviations for SF-36 1-year follow-up are presented in Table S1. Outcomes for EQ-5D and VAS are listed in Table $S 2$ while the results of MFI-20 are presented in Table S3.

\section{Discussion}

AFib is present in $1 \%$ to $6 \%$ of patients presenting for CABG or aortic valve surgery, and up to $50 \%$ of patients undergoing mitral valve surgery (34-36). In the general population, AFib is a marker of advanced cardiovascular disease, which only increases with age. Patients with mitral 


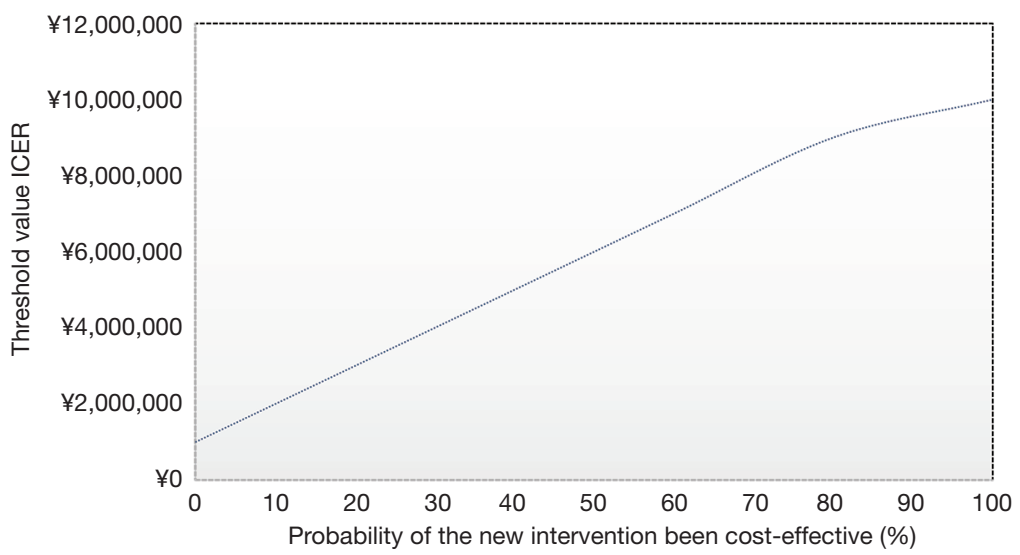

Figure 1 Acceptability curve of costs per quality-adjusted life years. ICER, incremental cost-effectiveness ratio.

valve dysfunction and associated AFib have a higher NYHA functional class, greater left atrial size, and a more severe left ventricular dysfunction $(36,37)$ as compared to patients without AFib. Accordingly, Quader et al. published a clinical report on CABG patients confirming similar associations with AFib in this population (36). AFib is associated with increased morbidity and mortality in CABG patients and patients undergoing valvular surgeries $(35,36,38)$. AFib is also, however, an independent risk factor for cardiac morbidity (stroke, thromboembolism, and anticoagulantrelated bleeding) (38).

This study used a single-center cardiac surgery database (one of the major designated centers for AFib treatment procedures in China) to describe the contemporary utilization of AFib correction surgery. The study assessed the cost-effectiveness, HrQoL, and the associated risk of morbidity or mortality in combining surgical AFib correction with valvular, and CABG surgery. We found an increased performance with AFib correction procedures during this study; however, the surgical procedure was associated with a need for postoperative permanent pacemaker implantation, a potential adverse outcome for surgical AFib corrective procedures (39). We also found out that morbidity risk varied with the type or kind of method (CABG with single or double valve replacement). These results were consistent with previous studies, including a prospective randomized study (40) and a retrospective casematched study (41).

However, the simultaneous AFib Procedure did not substantively increase the operative mortality rate. Our study further shows that an additional ablation surgery is not cost-effective compared to surgery as usual (42), as the cost of surgery in all the subcategories was significantly higher. When prices for all the subgroups were compared to their effectiveness (based on a regional societal perspective of general cardiac surgery in Mainland China) (38), this resulted in an ICER of $¥ 542,287,667(\$ 76,513,227)$ per QALY gained (the extra society is willing to pay to obtain a QALY).

Nonetheless, even with our study showing concomitant AFib to be less cost-effective, a recent review (43) showed promising positive results with AFib surgery versus no AFib surgery. Notwithstanding, despite the promising results as reported in the literature, it only but leaves us with questions like: (I) should we still carry out surgical AFib ablations, not minding the cost implications? (II) should AFib ablation be provided as a surgical treatment option for patients with currently no standardized rationale (diverse ablation practices), and the underrepresentation of long-term patient-reported outcomes within existing AFib intervention trials?

If "yes", is it worth the effort even when sinus rhythm is not achieved in most of the cases? With recommendations from STS guidelines (20), which adds "to restore sinus rhythm" rather than to improve QoL as the purpose for intervention. If "no", however, what are the possible set out guidelines to back-up such (clinical) decision? To answer such difficult key questions and or justify such clinical decisions, one needs to thoroughly examine the four essential guidelines (7,8,18-20).

Having gone through the guidelines with the known AFib associated risk, it is difficult to see a reason "not" to offer concomitant AFib surgery with chances evaporating when the chest has been closed. As one should bear in mind that, AFib is an independent risk factor for cardiac 
morbidity with an increased mortality rate $(35,36,38)$, and symptomatic patients would have to undergo cardiac surgery. Hence in clinical practice, it appears natural to conclude that one should always carry out concomitant AFib surgery in symptomatic patients with palpitations when the opportunity arises. However, of course, not all AFib patients have palpitations as their presenting symptoms could easily be attributable to other coexisting cardiac conditions.

Nevertheless, justifying this adds to the total cost of the operation. Although our study and other evidence suggest that there is no overall increase in mortality and severe morbidity as a result of an add-on catheter ablation surgery $(10,43)$, the enthusiasm for performing concomitant AFib surgery by surgeons should be tempered. Therefore, as seen in our study, add-on catheter ablation surgery is costly in terms of time and resources. It increases the bypass and cross-clamp times, requires dissection in areas around the heart typically left untouched, and open-heart chambers that would otherwise be left unopened.

However, restoring sinus rhythm through AFib surgery may not guarantee freedom from the risks associated with AFib (44). Most importantly, patients are primarily interested in feeling better and living longer rather than care about whether their ECG is "normal" or show a regular sinus rhythm. Besides, the increased operative burden, duration, cost, and the high rate of permanent pacemaker implantation $(10,43)$, as also noted in our study, are not the only associated risk factors of AFib surgery. Hence, enthusiastic surgeons must be aware that the additional risk of air embolism into heart chambers is doubled with the procedure, making AFib ablative procedures, not a venture to be embarked upon lightly in terms of safety. More so, the apparent discrepancies in reporting outcomes (44-46) by enthusiasts of the technique only have flooded the research field to some extent.

Thus, is it worth the effort? Most certainly, yes. However, it is heavily dependent on the indication (which remains controversial), and the settings (e.g., institute experience, and comorbidities). For instance, if the reported atrial contractility is truly restored in both short and long-term cases given its episodic nature then, the patient may stand to benefit substantially in terms of both survivals, QoL, and the cost of the procedure most certainly. Finally, below we highlight possible options to better tailor the interventional treatment of AFib in order to avoid "unnecessary" surgical ablative therapeutic decisions which in the long run, may prove as not to be cost-effective:

(I) Epidemiologic studies (47): epidemiologic studies have identified several potentially modifiable risk factors for AFib, such as including obesity, diabetes mellitus, metabolic syndrome, cigarette smoking, hypertension, obstructive sleep apnea, and excessive alcohol intake (47). Thus, prevention efforts should be aimed at individuals with the highest risk.

(II) Substrate-guided therapy: Though the recent trials, including STAR AF II, have demonstrated little or no clinical benefit with substrate characterization, a refined substrate characterization along with prospective delineation of AFib triggers and drivers will be necessary. The 4th Atrial Fibrillation NETwork (AFNET)/European Heart Rhythm Association (EHRA) consensus conference, however, proposed a new clinical classification of AFib, namely (i) distinct types (postoperative, focal, and monogenic induced AFib), and (ii) convoluted subtypes (valvular, polygenic, and AFib amongst the older population). With this classification, patients are assigned to their respective groups, whereas AFib not fulfilling these definitions would be "unclassified" (48). However, the limiting factor to the classification were cases of an "overlap", were an "unclassified AFib" was the typical outcome. Nonetheless, an alternative substrate-based approach (the EHRA classes I to IV) was, however, proposed by the EHRA/ Heart Rhythm Society (HRS)/Asia Pacific Heart Rhythm Society (APHRS)/Latin American Society of Electrophysiology and Cardiac Stimulation Congress (SOLAECE) consensus group (cardiomyocyte-dependent, fibrotic-dependent, mixed dependency, and primarily non-collagen atrial infiltration) (49).

(III) Genotype-directed therapy: numerous studies have identified rare forms of AFib with Mendelian inheritance, though this approach is yet to be tested, affected individuals with these mutations confer large effect sizes, and might, therefore, permit gene-directed pharmacotherapy. Hence, from a population perspective, the aim is to identify AFib subtypes or AFib-susceptible individuals who may benefit from preventive interventions or differentially respond to therapy (50-57).

\section{Conclusions}

While surgery for AFib has been performed for over two 
decades now, be it concomitant or stand-alone procedures and, more recently, hybrid methods, prospective multicenter clinical trials are needed to define better corrective AFib applicability. Though still, a fertile field for current and future exploration, identifying modifiable and non-modifiable risk factors for AFib will help curb "non-cost-effective" surgical ablative therapies by an enthusiast of the technique. Of course, there are still (possibly) more questions that remain to be asked and or addressed, but it is "advisable" to carry out concomitant AFib surgery in patients, however, subjected to cardiac surgery as it is a golden opportunity to treat the AFib. Notwithstanding, it all depends on what the patients or the society at large are willing to pay. In the meantime, as our knowledge for AFib expands, future studies must adopt consistent follow-up methodologies and procedural "success" definitions (58).

\section{Study limitations}

We acknowledge the fact that our study had some limitations: (I) the follow-up time in our research was quite short (1-year period) given the episodic nature of AFib. Therefore, what might seem to be a "regular sinus rhythm" at one point in time might, however, not be the same for the next 3-6 months and, or throughout the year. Thus, a 3- to 5-year follow-up period is ideal to ascertain if the procedure was "successful" or not, whereas ours was short. Hence, a shorter duration might not be an ideal time to ascertain if the procedure was "successful" as a successful procedure would be "cost-effective". Also, the results of our study might be, in part, probably skewed (possibly inevitable) since the surgical outcome for the majority of the participants who opted out were primarily not determined; (II) health care consumption in our study was limited to AFib related cost only; hence, the high costs during the follow-up could be caused by other comorbidities, and (III) it was a single-center study, a much more comprehensive (nationwide) or other designated centers in mainland China provincial data set for AFib add-on medical cost like Fuwai Hospital Beijing, Affiliated First Peoples Hospital Shanghai, and West China Hospital Sichuan was not ascertained and compared hence, AFib cost-effectiveness might either be under-reported or even possibly overestimated.

\section{Acknowledgments}

We like to thank Kwabena Acheampong, MPH. School of
Public Health, Central South University, Changsha, China, for his tremendous help in the statistical analysis of the data used in our study.

Funding: None.

\section{Footnote}

Reporting Checklist: The authors present the study in accordance with the MDAR reporting checklist. Available at http://dx.doi.org/10.21037/cdt-20-574

Data Sharing Statement: Available at http://dx.doi. org/10.21037/cdt-20-574

Conflicts of Interest: All authors have completed the ICMJE uniform disclosure form (available at http://dx.doi. org/10.21037/cdt-20-574). The authors have no conflicts of interest to declare.

Ethical Statement: The authors are accountable for all aspects of the work in ensuring that questions related to the accuracy or integrity of any part of the work are appropriately investigated and resolved. The study was conducted in accordance with the Declaration of Helsinki (as revised in 2013). The ethical committee for Xiangya Second Hospital of Central South University approved the study (No. 2018YFC1311204). The patients gave written informed consent to be included in the study.

Open Access Statement: This is an Open Access article distributed in accordance with the Creative Commons Attribution-NonCommercial-NoDerivs 4.0 International License (CC BY-NC-ND 4.0), which permits the noncommercial replication and distribution of the article with the strict proviso that no changes or edits are made and the original work is properly cited (including links to both the formal publication through the relevant DOI and the license). See: https://creativecommons.org/licenses/by-nc-nd/4.0/.

\section{References}

1. Chugh SS, Havmoeller R, Narayanan K, et al. Worldwide epidemiology of atrial fibrillation: a Global Burden of Disease 2010 Study. Circulation 2014;129:837-47.

2. Schnabel RB, Yin X, Gona P, et al. 50-year trends in atrial fibrillation prevalence, incidence, risk factors, and mortality in the Framingham Heart Study: a cohort study. Lancet 2015;386:154-62. 
3. Benjamin EJ, Levy D, Vaziri SM, et al. Independent risk factors for atrial fibrillation in a population-based cohort: the Framingham Heart Study. JAMA 1994;271:840-4.

4. Vaziri SM, Larson MG, Benjamin EJ, et al. Echocardiographic predictors of nonrheumatic atrial fibrillation: the Framingham Heart Study. Circulation 1994;89:724-30.

5. Van Wagoner DR, Piccini JP, Albert CM, et al. Progress toward the prevention and treatment of atrial fibrillation: A summary of the Heart Rhythm Society Research Forum on the Treatment and Prevention of Atrial Fibrillation, Washington, DC, December 9-10, 2013. Heart Rhythm 2015;12:e5-29.

6. Kirchhof P, Breithardt G, Bax J, et al. A roadmap to improve the quality of atrial fibrillation management: proceedings from the fifth Atrial Fibrillation Network/ European Heart Rhythm Association consensus conference. Europace 2016;18:37-50.

7. Camm AJ, Kirchhof P, Lip GY, et al. European Heart Rhythm Association and European Association for CardioThoracic Surgery. Guidelines for the management of atrial fibrillation: the Task Force for the Management of Atrial Fibrillation of the European Society of Cardiology (ESC). Eur Heart J 2010;31:2369-429.

8. January CT, Wann LS, Alpert JS, et al. 2014 AHA/ACC/ HRS guideline for the management of patients with atrial fibrillation: a report of the American College of Cardiology/American Heart Association Task Force on Practice Guidelines and the Heart Rhythm Society. J Am Coll Cardiol 2014;64:e1-76.

9. Kim MH, Johnston SS, Chu BC, et al. Estimation of total incremental health care costs in patients with atrial fibrillation in the United States. Circ Cardiovasc Qual Outcomes 2011;4:313-20.

10. Gillinov AM, Gelijns AC, Parides MK, et al. Surgical ablation of atrial fibrillation during mitral-valve surgery. $\mathrm{N}$ Engl J Med 2015;372:1399-409.

11. Benjamin EJ, Chen PS, Bild DE, et al. Prevention of atrial fibrillation: report from a national heart, lung, and blood institute workshop. Circulation 2009;119:606-18.

12. Roger VL, Go AS, Lloyd-Jones DM, et al. Heart disease and stroke statistics-2012 update: a report from the American Heart Association. Circulation 2012;125:e2-220.

13. Nattel S, Burstein B, Dobrev D. Atrial remodeling and atrial fibrillation: mechanisms and implications. Circ Arrhythm Electrophysiol 2008;1:62-73.

14. Schotten U, Verheule S, Kirchhof P, et al. Pathophysiological mechanisms of atrial fibrillation: a translational appraisal. Physiol Rev 2011;91:265-325.

15. Goette A, Kalman JM, Aguinaga L, et al. EHRA/ HRS/APHRS/SOLAECE expert consensus on atrial cardiomyopathies: definition, characterization, and clinical implication. Heart Rhythm 2017;14:e3-40.

16. Calkins H. Catheter ablation to maintain sinus rhythm. Circulation 2012;125:1439-45.

17. McCarthy PM, Kruse J, ShalliS, et al. Where does atrial fibrillation surgery fail? Implications for increasing effectiveness of ablation. J Thorac Cardiovasc Surg 2010;139:860-7.

18. Camm AJ, Lip GY, De Caterina R, et al. 2012 focused update of the ESC Guidelines for the management of atrial fibrillation: an update of the 2010 ESC Guidelines for the management of atrial fibrillation-developed with the special contribution of the European Heart Rhythm Association. Europace 2012;14:1385-413.

19. Kirchhof P, Benussi S, Kotecha D, et al. 2016 ESC Guidelines for the management of atrial fibrillation developed in collaboration with EACTS. Eur J Cardiothorac Surg 2016;50:e1-88.

20. Badhwar V, Rankin JS, Damiano RJ, et al. The Society of Thoracic Surgeons 2017 clinical practice guidelines for the surgical treatment of atrial fibrillation. Ann Thorac Surg 2017;103:329-41.

21. Collins R, MacMahon S. Reliable assessment of the effects of treatment on mortality and major morbidity, I: clinical trials. Lancet 2001;357:373-80.

22. Tricoci P, Allen JM, Kramer JM, et al. Scientific evidence underlying the ACC/AHA clinical practice guidelines. JAMA 2009;301:831-41.

23. Schumacher M, Olschewski M, Schulgen G. Assessment of quality of life in clinical trials. Stat Med 1991;10:1915-30.

24. Brooks R. Quality of life measures. Crit Care Med 1996;24:1769.

25. Fuster V, Ryden LE, Cannom DS, et al. ACC/AHA/ESC 2006 guidelines for the management of patients with atrial fibrillation-executive summary: A report of the American College of Cardiology/American Heart Association Task Force on Practice Guidelines and the European Society of Cardiology Committee for Practice Guidelines (Writing Committee to Revise the 2001 Guidelines for the Management of Patients With Atrial Fibrillation). J Am Coll Cardiol 2006;48:854-906.

26. Damiano RJ Jr, Schwartz FH, Bailey MS, et al. The Cox maze IV procedure: predictors of late recurrence. J Thorac Cardiovasc Surg 2011;141:113-21.

27. McHorney CA, Ware JE Jr, Raczek AE. The MOS 36- 
Item Short-Form Health Survey (S36): II. Psychometric and clinical tests of validity in measuring physical and mental health constructs. Med Care 1993;31:247-63.

28. Jenkins LS, Brodsky M, Schron E, et al. Quality of life in atrial fibrillation: The Atrial Fibrillation Follow-Up Investigation of Rhythm Management (AFFIRM) study. Am Heart J 2005;149:112-20.

29. Beck LB. The role of outcomes data in healthcare resource allocation. Ear Hear 2000;21:89S-96S.

30. Kuilman M, Bleeker JK, Hartman JA, et al. Long-term survival after out-of-hospital cardiac arrest: An 8-year follow-up. Resuscitation 1999;41:25-31.

31. Smets EM, Garssen B, Bonke B, et al. The multidimensional fatigue inventory (MFI) psychometric qualities of an instrument to assess fatigue. J Psychosom Res 1995;39:315-25.

32. Goossens ME, Rutten-van Molken MP, Vlaeyen JW, et al. The cost diary: a method to measure direct and indirect costs in cost effectiveness research. J Clin Epidemiol 2000;53:688-95.

33. Efron B, Tibshirani R. An introduction to the bootstrap. New York: Chapman \& Hall, 1993.

34. Cox JL. Intraoperative options for treating atrial fibrillation associated with mitral valve disease. J Thorac Cardiovasc Surg 2001;122:212-5.

35. Grigioni F, Avierinos JF, Ling LH, et al: Atrial fibrillation complicating the course of degenerative mitral regurgitation: determinants and long-term outcome. J Am Coll Cardiol 2002;40:84-92.

36. Quader MA, McCarthy PM, Gillinov AM, et al. Does preoperative atrial fibrillation reduce survival after coronary artery bypass grafting? Ann Thorac Surg 2004;77:1514-22.

37. Lim E, Barlow CW, Hosseinpour AR, et al. Influence of atrial fibrillation on outcome following mitral valve repair. Circulation 2001;104:I59-63.

38. Jessurun ER, van Hemel NM, Kelder JC, et al. Mitral valve surgery and atrial fibrillation: is atrial fibrillation surgery also needed? Eur J Cardiothorac Surg 2000;17:530-7.

39. Stulak JM, Sundt TM, Dearani JA, et al. Ten-year experience with the Cox-maze Procedure for atrial fibrillation: how do we define success? Ann Thorac Surg 2007;83:1319-24.

40. Doukas G, Samani NJ, Alexiou C, et al. Left atrial radiofrequency ablation during mitral valve surgery for continuous atrial fibrillation: a randomized controlled trial. JAMA 2005;294:2323-9.

41. Raanani E, Albage A, David TE, et al. The efficacy of the Cox/maze procedure combined with mitral valve surgery: a matched control study. Eur J Cardiothorac Surg 2001;19:438-42.

42. Ding JM, Zhang XZ, Hu XJ, et al. Analysis of hospitalization expenditures and influencing factors for inpatients with coronary heart disease in a tier-3 hospital in Xi'an, China: A retrospective study. Medicine (Baltimore) 2017;96:e9341.

43. Huffman MD, Karmali KN, Berendsen MA, et al. Concomitant atrial fibrillation surgery for people undergoing cardiac surgery. Cochrane Database Syst Rev 2016;2016:CD011814.

44. Ad N, Henry L, Shuman DJ, et al. A more specific anticoagulation regimen is required for patients after the Cox-maze Procedure. Ann Thorac Surg 2014;98:1331-8.

45. Loardi C, Alamanni F, Galli C, et al. Surgical Treatment of Concomitant Atrial Fibrillation: Focus onto Atrial Contractility. Biomed Res Int 2015;2015:274817.

46. Tinetti M, Costello R, Cardenas C, et al. Persistent atrial fibrillation is associated with inability to recover atrial contractility after MAZE IV surgery in rheumatic disease. Pacing Clin Electrophysiol 2012;35:999-1004.

47. Alonso A, Krijthe BP, Aspelund T, et al. Simple risk model predicts incidence of atrial fibrillation in a racially and geographically diverse population: the CHARGE-AF consortium. J Am Heart Assoc 2013;2:e000102.

48. Kirchhof P, Breithardt G, Aliot E, et al. Personalized management of atrial fibrillation: Proceedings from the fourth Atrial Fibrillation competence NETwork/European Heart Rhythm Association consensus conference. Europace 2013;15:1540-56.

49. Goette A, Kalman JM, Aguinaga L, et al. EHRA/ HRS/APHRS/SOLAECE expert consensus on atrial cardiomyopathies: definition, characterization, and clinical implication. Europace 2016;18:1455-90.

50. Ellinor PT, Lunetta KL, Albert CM, et al. Meta-analysis identifies six new susceptibility loci for atrial fibrillation. Nat Genet 2012;44:670-5.

51. Darbar D, Roden DM. Genetic mechanisms of atrial fibrillation: impact on response to treatment. Nat Rev Cardiol 2013;10:317-29.

52. Parvez B, Vaglio J, Rowan S, et al. Symptomatic response to antiarrhythmic drug therapy is modulated by a common single nucleotide polymorphism in atrial fibrillation. J Am Coll Cardiol 2012;60:539-45.

53. Parvez B, Shoemaker MB, Muhammad R, et al. Common genetic polymorphism at $4 \mathrm{q} 25$ locus predicts atrial fibrillation recurrence after successful cardioversion. Heart 
Rhythm 2013;10:849-55.

54. Shoemaker MB, Bollmann A, Lubitz SA, et al. Common genetic variants and response to atrial fibrillation ablation. Circ Arrhythm Electrophysiol 2015;8:296-302.

55. Choi EK, Park JH, Lee JY, et al. Korean Atrial Fibrillation (AF) Network: genetic variants for af do not predict ablation success. J Am Heart Assoc 2015;4:e002046.

56. Parvez B, Chopra N, Rowan S, et al. A common beta1adrenergic receptor polymorphism predicts favorable response to rate-control therapy in atrial fibrillation. J Am

Cite this article as: Iroegbu $\mathrm{CD}$, Chen $\mathrm{W}, \mathrm{Wu} \mathrm{X}$, Cheng $\mathrm{L}$, Zhang H, Wu M, Zhao Y, Liu LM, Yang J. Evaluating the cost-effectiveness of catheter ablation of atrial fibrillation. Cardiovasc Diagn Ther 2020;10(5):1200-1215. doi: 10.21037/cdt20-574
Coll Cardiol 2012;59:49-56.

57. Mohanty S, Hall AW, Mohanty P, et al. Novel association of polymorphic genetic variants with predictors of outcome of catheter ablation in atrial fibrillation: new directions from a prospective study (DECAF). J Interv Card Electrophysiol 2016;45:7-17.

58. Shemin RJ, Cox JL, Gillinov AM, et al. Guidelines for reporting data and outcomes for the surgical treatment of atrial fibrillation. Ann Thorac Surg 2007;83:1225-30. 


\begin{tabular}{|c|c|}
\hline $\begin{array}{l}\text { European quality of life (EuroQoL) } \\
\text { parameters }\end{array}$ & $\begin{array}{l}\text { Pre-operative } \\
\text { (M1/Baseline) }\end{array}$ \\
\hline Self-care (P value 0.001$)$ & \\
\hline Mitral + tricuspid + CABG + Cox Maz & IV $(n=1,012)$ \\
\hline Mean & 5.00 \\
\hline Std. deviation & 0.00 \\
\hline Aortic + CABG + Cox Maze IV $(n=819$ & \\
\hline Mean & 5.00 \\
\hline Std. deviation & 0.00 \\
\hline Mitral + tricuspid + aortic + $\mathrm{CABG}+\mathrm{C}$ & ox Maze IV $(n=1,1$ \\
\hline Mean & 4.86 \\
\hline Std. deviation & 0.34 \\
\hline Isolated CABG + Cox Maze IV $(n=91)$ & \\
\hline Mean & 5.00 \\
\hline Std. deviation & 0.00 \\
\hline Control $(n=7,258)$ & \\
\hline Mean & 3.30 \\
\hline Std. deviation & 0.46 \\
\hline Pain/discomfort (P value 0.001) & \\
\hline Mitral + tricuspid + CABG + Cox Maz & IV $(n=1,012)$ \\
\hline Mean & 5.00 \\
\hline Std. deviation & 0.00 \\
\hline Aortic + CABG + Cox Maze IV $(n=819$ & \\
\hline Mean & 5.00 \\
\hline Std. deviation & 0.00 \\
\hline Mitral + tricuspid + aortic $+C A B G+C$ & ox Maze IV $(n=1,1$ \\
\hline Mean & 5.00 \\
\hline Std. deviation & 0.00 \\
\hline Isolated CABG + Cox Maze IV ( $n=91)$ & \\
\hline Mean & 5.00 \\
\hline Std. deviation & 0.00 \\
\hline Control $(n=7,258)$ & \\
\hline Mean & 3.63 \\
\hline Std. deviation & 0.48 \\
\hline Mobility (P value 0.001$)$ & \\
\hline Mitral + tricuspid + $\mathrm{CABG}+\mathrm{Cox}$ Maz & IV $(n=1,012)$ \\
\hline Mean & 5.00 \\
\hline Std. deviation & 0.00 \\
\hline Aortic + CABG + Cox Maze IV $(n=819$ & \\
\hline Mean & 5.00 \\
\hline Std. deviation & 0.00 \\
\hline Mitral + tricuspid + aortic $+C A B G+C$ & ox Maze IV $(n=1,1$ \\
\hline Mean & 5.00 \\
\hline Std. deviation & 0.00 \\
\hline Isolated CABG + Cox Maze IV $(n=91)$ & \\
\hline Mean & 5.00 \\
\hline Std. deviation & 0.00 \\
\hline Control $(n=7,258)$ & \\
\hline Mean & 2.59 \\
\hline Std. deviation & 0.80 \\
\hline VAS (P value 0.001 ) & \\
\hline Mitral + tricuspid + CABG + Cox Maz & IV $(n=1,012)$ \\
\hline Mean & 5.00 \\
\hline Std. deviation & 0.00 \\
\hline Aortic + CABG + Cox Maze IV $(n=819$ & \\
\hline Mean & 5.00 \\
\hline Std. deviation & 0.00 \\
\hline Mitral + tricuspid + aortic + CABG $+C$ & ox Maze IV $(n=1,1$ \\
\hline Mean & 4.27 \\
\hline Std. deviation & 0.45 \\
\hline Isolated CABG + Cox Maze IV (n=91) & \\
\hline Mean & 5.00 \\
\hline Std. deviation & 0.00 \\
\hline Control $(n=7,258)$ & \\
\hline Mean & 3.05 \\
\hline Std. deviation & 0.22 \\
\hline Usual activities ( $P$ value 0.001 ) & \\
\hline Mitral + tricuspid + CABG + Cox Maz & IV $(n=1,012)$ \\
\hline Mean & 5.00 \\
\hline Std. deviation & 0.00 \\
\hline Aortic + CABG + Cox Maze IV $(n=819$ & \\
\hline Mean & 5.00 \\
\hline Std. deviation & 0.00 \\
\hline Mitral + tricuspid + aortic + CABG $+C$ & ox Maze IV $(n=1,1$ \\
\hline Mean & 5.00 \\
\hline Std. deviation & 0.00 \\
\hline Isolated CABG + Cox Maze IV $(n=91)$ & \\
\hline Mean & 5.00 \\
\hline Std. deviation & 0.00 \\
\hline Control $(n=7,258)$ & \\
\hline Mean & 4.28 \\
\hline Std. deviation & 0.45 \\
\hline Anxiety/depression (Pvalue $=0.001)$ & \\
\hline Mitral + tricuspid + CABG + Cox Maz & IV $(n=1,012)$ \\
\hline Mean & 4.00 \\
\hline Stdd deviation & 0.00 \\
\hline Aortic + CABG + Cox Maze IV $(n=819$ & \\
\hline Mean & 4.00 \\
\hline Std. deviation & 0.00 \\
\hline Mitral + tricuspid + aotric + $\mathrm{CABG}+\mathrm{C}$ & ox Maze IV $(n=1,1$ \\
\hline Mean & 4.00 \\
\hline Std. deviation & 0.00 \\
\hline Isolated CABG + Cox Maze IV ( $(n=91)$ & \\
\hline Mean & 4.00 \\
\hline Std. deviation & 0.00 \\
\hline Control $(n=7,258)$ & \\
\hline Mean & 3.17 \\
\hline Std. deviation & 0.38 \\
\hline
\end{tabular}


Table S3 Means and standard deviations of Multidimensional Fatigue Inventory (MFI) scores for 1-year follow-up in all "add-on" subcategories vs. "surgery as usual"

\begin{tabular}{|c|c|c|c|c|}
\hline $\begin{array}{l}\text { Multidimensional Fatigue Inventory (MFI) } \\
\text { parameters }\end{array}$ & $\begin{array}{l}\text { Pre-operative } \\
\text { (M1/Baseline) }\end{array}$ & $\begin{array}{l}\text { Three months } \\
\text { postoperative (M2) }\end{array}$ & $\begin{array}{c}\text { Six months } \\
\text { postoperative (M3) }\end{array}$ & $\begin{array}{l}\text { Twelve months } \\
\text { postoperative (M4) }\end{array}$ \\
\hline \multicolumn{5}{|l|}{ Reduced activity (P value 0.001 ) } \\
\hline \multicolumn{5}{|c|}{ Mitral + tricuspid + CABG + Cox Maze IV $(n=1,012)$} \\
\hline Mean & 3.56 & 3.12 & 4.19 & 5.00 \\
\hline Std. deviation & 0.49 & 0.99 & 0.39 & 0.00 \\
\hline \multicolumn{5}{|l|}{ Aortic + CABG + Cox Maze IV $(n=819)$} \\
\hline Mean & 3.86 & 4.05 & 4.00 & 5.00 \\
\hline Std. deviation & 1.28 & 1.39 & 0.00 & 0.00 \\
\hline \multicolumn{5}{|c|}{ Mitral + tricuspid + aortic + CABG + Cox Maze IV $(n=1,146)$} \\
\hline Mean & 2.89 & 4.00 & 5.00 & 5.00 \\
\hline Std. deviation & 0.31 & 0.05 & 0.05 & 0.00 \\
\hline \multicolumn{5}{|l|}{ Isolated CABG + Cox Maze IV ( $n=91)$} \\
\hline Mean & 4.00 & 5.00 & 4.00 & 5.00 \\
\hline Std. deviation & 0.00 & 0.00 & 0.00 & 0.00 \\
\hline \multicolumn{5}{|l|}{ Control $(n=7,258)$} \\
\hline Mean & 3.85 & 2.25 & 1.70 & 1.10 \\
\hline Std. deviation & 0.82 & 0.43 & 0.46 & 0.30 \\
\hline Mental fatigue (P value 0.001 ) & & & & \\
\hline Mitral + tricuspid + CABG + Cox Maze I & $=1,012)$ & & & \\
\hline Mean & 2.58 & 1.00 & 2.00 & 3.00 \\
\hline Std. deviation & 0.49 & 0.00 & 0.00 & 0.00 \\
\hline Aortic + CABG + Cox Maze IV $(n=819)$ & & & & \\
\hline Mean & 3.00 & 1.00 & 2.00 & 3.00 \\
\hline Std. deviation & 0.00 & 0.00 & 0.00 & 0.00 \\
\hline Mitral + tricuspid + aortic + CABG + Co & aze IV $(n=1,146)$ & & & \\
\hline Mean & 1.09 & 1.36 & 2.00 & 3.00 \\
\hline Std. deviation & 0.29 & 0.48 & 0.00 & 0.00 \\
\hline Isolated CABG + Cox Maze IV ( $\mathrm{n}=91)$ & & & & \\
\hline Mean & 3.00 & 1.00 & 2.00 & 3.00 \\
\hline Std. deviation & 0.00 & 0.00 & 0.00 & 0.00 \\
\hline Control $(n=7,258)$ & & & & \\
\hline Mean & 2.95 & 2.29 & 1.27 & 1.10 \\
\hline Std. deviation & 0.22 & 0.45 & 0.45 & 0.29 \\
\hline Physical fatigue (P value 0.001 ) & & & & \\
\hline Mitral + tricuspid + CABG + Cox Maze I & $=1,012)$ & & & \\
\hline Mean & 5.00 & 3.20 & 3.00 & 5.00 \\
\hline Std. deviation & 0.00 & 0.65 & 0.00 & 0.00 \\
\hline Aortic + CABG + Cox Maze IV $(n=819)$ & & & & \\
\hline Mean & 5.00 & 4.00 & 3.00 & 5.00 \\
\hline Std. deviation & 0.00 & 0.00 & 0.00 & 0.00 \\
\hline Mitral + tricuspid + aortic + CABG + Cox & aze IV $(n=1,146)$ & & & \\
\hline Mean & 4.43 & 2.01 & 3.00 & 5.00 \\
\hline Std. deviation & 0.49 & 0.10 & 0.00 & 0.00 \\
\hline Isolated CABG + Cox Maze IV $(n=91)$ & & & & \\
\hline Mean & 5.00 & 4.00 & 3.00 & 5.00 \\
\hline Std. deviation & 0.00 & 0.00 & 0.00 & 0.00 \\
\hline Control $(n=7,258)$ & & & & \\
\hline Mean & 4.42 & 3.79 & 3.41 & 2.44 \\
\hline Std. deviation & 0.49 & 0.41 & 0.49 & 0.49 \\
\hline Reduced motivation (P value 0.001 ) & & & & \\
\hline Mitral + tricuspid + CABG + Cox Maze I & $=1,012)$ & & & \\
\hline Mean & 1.59 & 1.94 & 3.00 & 4.00 \\
\hline Std. deviation & 0.49 & 0.87 & 0.00 & 0.00 \\
\hline Aortic + CABG + Cox Maze IV $(n=819)$ & & & & \\
\hline Mean & 2.94 & 1.00 & 3.00 & 4.00 \\
\hline Std. deviation & 0.24 & 0.00 & 0.00 & 0.00 \\
\hline Mitral + tricuspid + aortic + CABG + Cor & aze IV $(n=1,146)$ & & & \\
\hline Mean & 2.37 & 2.99 & 3.00 & 4.00 \\
\hline Std. deviation & 0.92 & 1.00 & 0.00 & 0.00 \\
\hline Isolated CABG + Cox Maze IV $(n=91)$ & & & & \\
\hline Mean & 3.00 & 1.00 & 3.00 & 4.00 \\
\hline Std. deviation & 0.00 & 0.00 & 0.00 & 0.00 \\
\hline Control $(n=7,258)$ & & & & \\
\hline Mean & 4.15 & 3.36 & 2.43 & 1.43 \\
\hline Std. deviation & 0.36 & 0.48 & 0.49 & 0.49 \\
\hline General fatigue ( $P$ value 0.001 ) & & & & \\
\hline Mitral + tricuspid + CABG + Cox Maze I & $=1,012)$ & & & \\
\hline Mean & 5.00 & 4.79 & 4.00 & 2.23 \\
\hline Std. deviation & 0.00 & 0.41 & 0.00 & 0.42 \\
\hline Aortic + CABG + Cox Maze IV $(n=819)$ & & & & \\
\hline Mean & 5.00 & 5.00 & 4.00 & 3.00 \\
\hline Std. deviation & 0.00 & 0.00 & 0.00 & 0.00 \\
\hline Mitral + tricuspid + aortic $+C A B G+C o$ & aze IV $(n=1,146)$ & & & \\
\hline Mean & 5.00 & 4.00 & 4.00 & 2.00 \\
\hline Std. deviation & 0.00 & 0.05 & 0.00 & 0.05 \\
\hline Isolated CABG + Cox Maze IV $(n=91)$ & & & & \\
\hline Mean & 5.00 & 5.00 & 4.00 & 3.00 \\
\hline Std. deviation & 0.00 & 0.00 & 0.00 & 0.00 \\
\hline Control $(n=7,258)$ & & & & \\
\hline Mean & 4.44 & 3.05 & 2.56 & 1.44 \\
\hline Std. deviation & 0.49 & 0.21 & 0.49 & 0.49 \\
\hline
\end{tabular}

Data presented as mean $\pm \mathrm{SD}$. CABG, coronary arterial bypass. 